SCIENTIFIC LETTER

\title{
Association of the ile405val mutation in cholesteryl ester transfer protein gene with risk of acute myocardial infarction
}

\author{
G K Andrikopoulos, D J Richter, E W Needham, M N Zairis, E N Karabinos, E J Gialafos, \\ P E Dilaveris, K E Paravolidakis, K G Kappos, E G Papasteriadis, F G Kardaras, S G Foussas, \\ C I Stefanadis, J E Gialafos, R K Mattu, P K Toutouzas
}

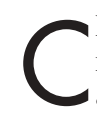
holesteryl ester transfer protein (CETP) not only regulates removal of excess cholesterol to the liver but also mediates the transfer of esterified hydrophobic cholesterol to the potentially atherogenic low density lipoprotein (LDL) and intermediate density lipoprotein (IDL) particles. The Ile405Val mutation in the CETP gene, caused by an $A>G$ mutation in codon 405 of exon 14, which is located in chromosome 16, has been related to decreased activity of the enzyme, ${ }^{1}$ increased but possibly dysfunctional high density lipoprotein (HDL) cholesterol, and increased risk for ischaemic heart disease ${ }^{2}$ in white women. The primary objective of this specifically designed, prospective study was to examine the influence of the Ile405Val mutation on risk of acute myocardial infarction (AMI) in a low coronary risk white population.

\section{METHODS}

The GEMIG study (genetics and epidemiology of acute myocardial infarction in the Greek population) was designed to evaluate the genetic predisposition of myocardial infarction and prognosis after AMI in the Greek population. Nine cardiac departments in three cities (Athens, Piraeus, and Thesalonici) in Greece, and the Department of Biological Sciences of Warwick University, have participated in this study. Blood samples for genetic analyses and successful genotyping for the Ile405Val mutation occurred in 1625 patients, out of a total of 1749 consecutive eligible patients who had been enrolled in the GEMIG study between October 1997 and March 1999. The control group consisted of 805 adults (aged $>30$ years old) who were randomly selected from the city catalogues. Blood samples for genetic analyses were obtained from 794 of the study participants, but 32 out of the 794 eligible subjects had clinical or electrocardiographic evidence of a possible myocardial infarction and thus were not included in the control group. Out of the remaining 762 subjects, 735 were successfully genotyped for the Ile405Val mutation. The study protocol affected neither diagnostic evaluation nor therapeutic interventions of the studied patients, and complied with the Declaration of Helsinki. The scientific committee of the study and the local ethics committee approved the study protocol and informed consent for the genetic analysis was obtained from the study participants or their guardians.

The CETP Ile405Val mutation was analysed by polymerase chain reaction (PCR) amplification using the following primer set: 5' upstream: 5'-AAT-gCT-TgT-CCA-ggC-CgTgCA-gCA-T-3' and 3' downstream: 5'-CAg-TTT-CCC-CTCCAg-CCC-ACA-CTT-A-3' ${ }^{\prime}$ PCR products were then digested with 5 units of FokI restriction enzyme. Digestion of the PCR products indicated presence of the Val405 genotype.

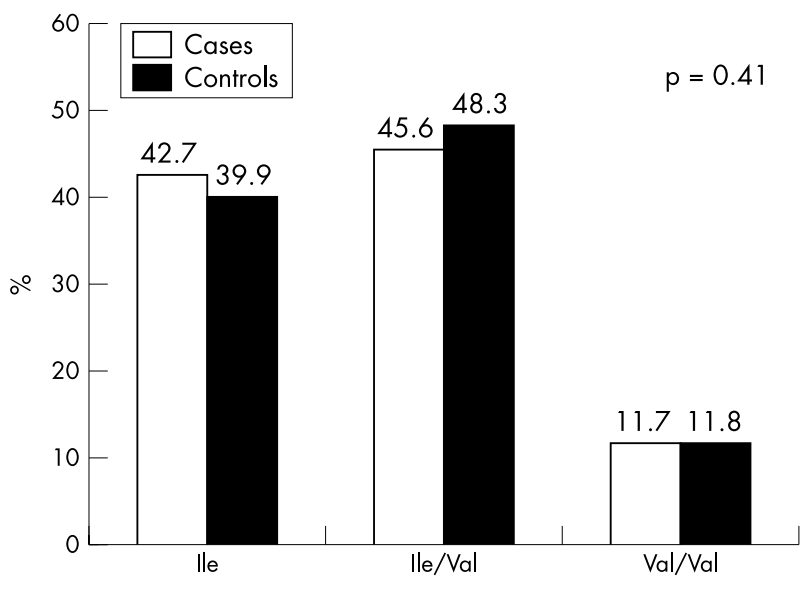

Figure 1 Frequencies of the genotypes of the lle $405 \mathrm{Val}$ mutation in CETP gene. The presented values denote percentages.

$\chi^{2}$ Tests and Student's $t$ test were used in univariate analysis, as appropriate. Multivariate logistic regression analysis, with an allowance for age, sex, hypercholesterolaemia, hypertension, diabetes mellitus, smoking, and family history for coronary artery disease, was used to explore the impact of the Val/Val genotype on risk of AMI.

\section{RESULTS}

The observed frequencies of the studied genotypes of the CETP gene are shown in fig 1 . The frequencies of the studied alleles were in Hardy-Weinberg equilibrium in both cases $\left(\chi^{2}=0.13, \mathrm{p}>0.1\right)$ and controls $\left(\chi^{2}=1.72, \mathrm{p}>0.1\right)$. There was no significant difference in the frequency of the studied genotypes between cases and controls in univariate analysis. Furthermore, the Val/Val genotype was not found to be an independent predictor of AMI in multivariate logistic regression analysis adjusted for age, sex, and the major coronary risk factors (relative risk (RR) $0.98,95 \%$ confidence interval (CI) 0.83 to $1.16, \mathrm{p}=0.802)$.

The mean (SD) age of patients with AMI carrying the Ile/ Ile, Ile/Val and Val/Val genotype was 63 (12), 62 (13) and 62 (12) years, respectively $(\mathrm{p}=0.578)$. The mean age of controls carrying the same genotypes was 58 (15), 58 (15) and 56 (16) years, respectively $(\mathrm{p}=0.369)$. Age was not

Abbreviations: AMI, acute myocardial infarction; CETP, cholesteryl ester transfer protein; IDL, intermediate density lipoprotein; GEMIG, genetics and epidemiology of acute myocardial infarction in the Greek population; HDL, high density lipoprotein; LDL, low density lipoprotein; $\mathrm{PCR}$, polymerase chain reaction 
found to be significantly and independently associated with the presence of the $\mathrm{Val} / \mathrm{Val}$ genotype in multivariate analysis among cases (odds ratio (OR) $0.999,95 \%$ CI 0.987 to 1.012 , $\mathrm{p}=0.936$ ), controls (OR 1.010, 95\% CI 0.995 to 1.025 , $\mathrm{p}=0.203$ ) or in the whole study population (OR $1.014,95 \%$ CI 0.994 to $1.031, \mathrm{p}=0.433$ ). The Ile405Val genotypes were also studied in relation to smoking status, diabetes mellitus, hypercholesterolaemia, hypertension, and family history for coronary artery disease. None of the aforementioned variables was significantly and independently associated with the presence of the mutated genotype in multivariate analysis.

\section{DISCUSSION}

The main finding of this study is that the Ile405Val mutation in the gene encoding CETP is not associated with increased risk of AMI. Furthermore, in contrast to previous reports, there was no measurable sex specific effect of the Val/Val genotype on risk of AMI.

The frequencies of the Ile/Ile, Ile/Val, and Val/Val genotypes in our study were similar to those reported by the Copenhagen City heart study investigators, ${ }^{2}$ and comparable to those presented by Gudnason and co-workers, who examined the frequency of the Val allele in small population samples enrolled from 11 European countries participating in the European atherosclerosis research study (EARS) II study. ${ }^{3}$

There is a plethora of data in the literature supporting the theory that homozygocity for the Val allele of the Ile405Val mutation affects activity of the CETP gene. There is also a considerable body of evidence suggesting that deficiency of the CETP activity may contribute to increased, but possibly dysfunctional, HDL cholesterol which may actually increase risk of ischaemic heart disease at the population level. In contrast to our results, Agerholm-Larsen and colleagues from the Copenhagen City heart study have reported that up to $24 \%$ of female ischaemic heart disease risk in the Danish population can be attributed to that mutation of the CETP gene. $^{2}$ Indeed, the population sample of the study by Agerholm-Larsen was larger and consequently this study was more likely to detect minor influences of the studied mutation in subgroups of the study population. Furthermore, differences in the atherogenicity of the cardiovascular risk factors between northern and southern European populations may also account for the partly discrepant results regarding female risk of ischaemic heart disease. Yamada and colleagues have recently verified the lack of any effect of the studied mutation on genetic risk of AMI, screening 112 candidate genes in the Japanese population. ${ }^{4}$

One could argue that a different methodology might have led us to different results. In other similar association studies, the control group was comprised of unaffected age and sex matched relatives of the patients, from unselected patients examined in another department of the hospital (for example blood donors), or from patients without coronary artery stenosis, who had undergone coronary angiography. The control group in this study was a randomly selected sample of adults derived from the city catalogues of a population which included urban and rural populations in proportion to the general population. Given that all controls were carefully examined by cardiologists, all had a surface ECG, and some of them underwent echocardiography when indicated, the misclassification of subjects in the control group is not likely to have affected our results.

The main limitation of this study is the lack of homogeneous data concerning lipid metabolism in relation to CETP activity.

\section{ACKNOWLEDGEMENTS}

The authors are indebted to all the cardiologists and to all the directors of the cardiac departments that participated in the study. The first author was supported by the Hellenic Heart Foundation (Research Fellowship, 1998-1999), and by the European Society of Cardiology (Research Fellowship of the ESC, 1999-2000). The second author was also supported by a Research Fellowship of the European Society of Cardiology (1998-1999).

\section{Authors' affiliations}

G K Andrikopoulos, E N Karabinos, K G Kappos, F G Kardaras,

Cardiac Department, Evaggelismos Hospital, Athens, Greece

D J Richter, Euroclinic Hospital, Athens, Greece

E W Needham, University of Warwick, Warwick, UK

M N Zairis, Tzaneion Hospital, Piraeus, Greece

E J Gialafos, Department of Therapeutics, Alexandra Hospital, Athens, Greece

P E Dilaveris, Polykliniki Hospital, Athens, Greece

K E Paravolidakis, E G Papasteriadis, Cardiac Department, Agios Panteleimon Hospital, Nikaia, Greece

S G Foussas, Cardiac Department, Tzaneion Hospital, Piraeus, Greece C I Stefanadis, J E Gialafos, P K Toutouzas, University of Athens Medical School, Hippokration Hospital, Athens, Greece

R K Mattu, Walsgrave Hospital, Coventry, UK

This study was carried out on behalf of the GEMIG study investigators

Correspondence to: George K Andrikopoulos, 9 Yrkanias Street, 11142 Athens, Greece; geomabuz@otenet.gr

Accepted 5 February 2004

\section{REFERENCES}

1 Inazu A, Brown ML, Hesler CB, et al. Increased high-density lipoprotein levels caused by a common cholesteryl-ester transfer protein gene mutation. N Engl J Med 1990;323:1234-8.

2 Agerholm-Larsen B, Nordestgaard BG, Steffensen R, et al. Elevated HDL cholesterol is a risk factor for ischaemic heart disease in white women when caused by a common mutation in the cholesteryl ester transfer protein gene. Circulation 2000;101:1907-12.

3 Gudnason V, Kakko S, Nicaud V, et al. Cholesteryl ester transfer protein gene effect on CETP activity and plasma high-density lipoprotein in European populations. Eur J Clin Invest 1999;29:116-28.

4 Yamada $\mathrm{Y}$, Izawa $\mathrm{H}$, Ishihara $\mathrm{H}$, et al. Prediction of the risk of myocardial infarction from polymorphisms in candidate genes. N Engl J Med 2002;347:1916-23 